\title{
Effect of hyperglycemia and hyperinsulinemia on glutathione peroxidase activity in non-obese women with polycystic ovary syndrome
}

\author{
Ana Savic-Radojevic, ${ }^{1}$ Ivana Bozic Antic, ${ }^{2}$ Vesna Coric, ${ }^{1}$ Jelica Bjekic-Macut, ${ }^{3}$ \\ Tanja Radic, ${ }^{1}$ Milos Zarkovic, ${ }^{2}$ Tatjana Djukic, ${ }^{1}$ Marija Pljesa-Ercegovac, ${ }^{1}$ \\ Dimitrios Panidis, ${ }^{4}$ Ilias Katsikis, ${ }^{4}$ Tatjana Simic, ${ }^{1}$ Djuro Macut ${ }^{2}$
}

${ }^{1}$ Institute of Medical and Clinical Biochemistry, ${ }^{2}$ Clinic for Endocrinology, Diabetes and Metabolic Diseases, ${ }^{3} \mathrm{CHC}$ Bežanijska kosa; Faculty of Medicine, University of Belgrade, Belgrade, Serbia; ${ }^{4}$ Division of Endocrinology and Human Reproduction, $2^{\text {nd }}$ Department of Obstetrics and Gynecology, Aristotle University of Thessaloniki, Thessaloniki, Greece

\begin{abstract}
OBJECTIVE: In order to gain deeper insight into molecular mechanisms underlying oxidative stress (OS) and its relation to insulin resistance and hyperandrogenemia, plasma markers of OS and antioxidant glutathione-peroxidase (GPX) activity were studied in non-obese polycystic ovary syndrome (PCOS) women via the oral glucose tolerance test (OGTT) and hyperinsulinemic euglycemic clamp. DESIGN: In 36 PCOS women, plasma nitrotyrosine, thiol groups, uric acid (UA) and GPX activity were studied during OGTT and clamp. Insulin resistance was assessed by the homeostasis model (HOMA-IR), quantitative insulin sensitivity check index (QUICKI), Matsuda insulin sensitivity index (ISI) and M/I ratio. RESULTS: In PCOS patients, significant positive correlations were obtained for $U A$ with testosterone $(r=0.385, p=0.039)$ as well as indices of insulin resistance. Acute hyperglycemia during OGTT induced alteration in both OS markers and GPX. The change in nitrotyrosine and GPX during OGTT correlated with testosterone $(r=0.543, p=0.036$ and $r=-0.457, p=0.025$, respectively). The most significant association was found between OS markers and ISI. CONCLUSIONS: Our results indicate that non-obese PCOS women are prone to oxidative stress induced by hyperglycemia, but this seems not to be related to the direct effect of hyperinsulinemia during clamp. Oxidative stress markers correlated with indices of insulin resistance and circulating testosterone.
\end{abstract}

Key words: Glutathione peroxidase, Insulin resistance, Nitrotyrosine, Oxidative stress, Polycystic ovary syndrome

Address for correspondence:

Djuro Macut, MD, PhD, Clinic for Endocrinology, Diabetes and Diseases of Metabolism, Faculty of Medicine, University of Belgrade, Dr Subotića 13, 11000 Belgrade, Serbia;

Fax: +381 112685357; E-mail: djmacut@gmail.com

Received: 27-6-2013, Accepted:6-8-2013

\section{INTRODUCTION}

Polycystic ovary syndrome (PCOS), a frequent disorder of reproductive-aged women, is accompanied by oxidative stress in which increased production of free radicals is followed by decreased serum total 
antioxidant levels. ${ }^{1-5}$ Furthermore, it has been shown that even lean women with PCOS exhibit oxidative stress. ${ }^{4,5}$ Nevertheless, the molecular mechanisms underlying oxidative stress and its link with insulin resistance and hyperandrogenism remain unclear.

It is well known that in PCOS, glucose ingestion induces increased production of reactive oxygen species (ROS) together with an inflammatory response that is independent of obesity. ${ }^{2,6}$ These findings are mainly based on observed increased ROS generation and NADPH activity as well as increased activation of NFKB and TNF $\alpha$ mRNA content of mononuclear cells (MNCs) isolated from PCOS women after the glucose challenge. ${ }^{2,6}$ In contrast, MNCs of normal weight ovulatory women are less sensitive to hyperglycemia and exhibit a lower increase in ROS generation in response to glucose ingestion. ${ }^{6}$ It has been suggested that both insulin resistance and hyperandrogenemia might be responsible for this pro-oxidant response. Specifically, in the most recent findings of Gonzales et al (2011), acute oral androgen administration in normal weight ovulatory women promoted MNC activation and increased MNC sensitivity to glucose ingestion in a similar manner to PCOS. ${ }^{7}$ This implies that hyperandrogenism, the hallmark feature of PCOS, might play the role of progenitor of diet-induced oxidative stress in the disorder. Indeed, the data on vascular smooth muscle cells from male Wistar-Kyoto rats and spontaneously hypertensive rats showed that testosterone treatment causes increased ROS generation as well as increased levels of Nox 1 and Nox 4 mRNA and expression of the NADPH subunit, p47phox. ${ }^{8}$ Based on these findings, it could be speculated that transient increase in ROS generation during hyperglycemia in PCOS is associated with both insulin resistance and increased testosterone production. Consequently, the question arises whether antioxidant enzymes are involved in this phenomenon.

In order to gain deeper insight into the association of hyperglycemia-induced oxidant stress with both hyperandogenism and insulin resistance, in this study we examined the correlation between markers of oxidative damage as well as plasma GPX activity in PCOS patients and parameters of insulin resistance together with testosterone levels.

\section{SUBJECTS AND METHODOLOGY}

\section{Subjects}

Thirty-six patients with PCOS and 11 age- and BMI-matched healthy women with regular ovulatory menstrual cycles were included in the study. The diagnosis of PCOS was made on the basis of the revised 2003 Rotterdam ESHRE/ARSM consensus criteria (2004). ${ }^{9}$ PCOS index case qualifications were applied according to the definitions of Laven et al (2002) for oligomenorrhea and amenorrhea. ${ }^{10}$ Anovulation was defined as serum progesterone less than $10 \mathrm{nmol} / \mathrm{L}$, or in patients with normal menses at least 2 consecutive low levels of serum progesterone $(<10 \mathrm{nmol} / \mathrm{L})$. Hirsutism was defined according to the modified Ferriman-Gallwey scoring system: a woman with a score $\geq 8$ points was considered hirsute. ${ }^{11}$ Hyperandrogenemia was defined by serum total testosterone $>2 \mathrm{nmol} / \mathrm{L}$, which was based on examination of 56 nonselected women presenting for routine controls who were not hirsute, had regular cycles and had received no hormonal therapy. ${ }^{12}$ Transvaginal ultrasonography was used for the diagnosis of polycystic ovaries. ${ }^{13}$ In all examined subjects, body mass index (BMI) was calculated and waist circumference (WC) determined.

In PCOS patients, impaired fasting glucose (fasting venous glucose $>6 \mathrm{mmol} / \mathrm{L}$ ), pregnancy, hypothyroidism, nonclassic 21-hydroxylase deficiency, hyperprolactinemia, Cushing's syndrome and androgensecreting tumors were excluded by appropriate tests. No subjects had received any oral contraceptives, glucocorticoids, anti-androgens, ovulation inducing agents, anti-diabetic and anti-obesity drugs, or other hormonal drugs for at least three months before the study. The study was approved by the Institutional Ethical Committees and written consent was obtained from all subjects.

\section{Biochemical and hormonal testing}

PCOS women and controls were investigated during the follicular phase of the menstrual cycle and those PCOS women with amenorrhea were evaluated after confirmation of low estrogen and progesterone levels. Plasma glucose $(\mathrm{mmol} / \mathrm{L})$ was determined by the glucose oxidase method (Randox) using the autoanalyser (Beckman, Austria). Uric acid 
( $\mathrm{mmol} / \mathrm{L}$ ) was determined by the colorimetric method (Randox, UK). High-sensitivity C-reactive protein (CRP, $\mathrm{ng} / \mathrm{mL}$ ) concentration was determined by the immunonephelometric method (DADE Behring, Germany). Fibrinogen ( $\mathrm{g} / \mathrm{L})$ was calculated from the prothrombin time expressed in seconds and converted to percentages of normal by using a reference curve which was established by serial dilutions of calibration plasma (Standard human plasma, DADE Boehring, Germany). Serum insulin (mU/L) concentrations were determined by radioimmunoassay [RIA INSULIN (PEG), INEP, Belgrade, Serbia]. Insulin resistance (IR) was determined by the homeostasis model assessment [HOMA-IR $=$ insulin $(\mathrm{mU} / \mathrm{L}) \times$ glucose $(\mathrm{mmol} / \mathrm{L}) / 22.5],{ }^{14}$ quantitative insulin sensitivity check index [QUICKI=1-(Log (insulin, mU/L) + Log (glucose, $\mathrm{mg} / \mathrm{dL}$ ) $]^{15}$ and insulin sensitivity indexMatsuda [ISI Matsuda $_{10}=10000 /[$ Fasting glucose, $\mathrm{mg} / \mathrm{dL}$ $\times$ Fasting insulin, $\mathrm{mU} / \mathrm{L}) \times($ Mean glucose in OGTT, $\mathrm{mg} / \mathrm{dL} \times$ Mean insulin during OGTT, $\mathrm{mU} / \mathrm{L})] .{ }^{16} \mathrm{Se}-$ rum testosterone $(\mathrm{nmol} / \mathrm{L})$, androstenedione $(\mathrm{ng} / \mathrm{mL})$, dehydroepiandrosterone sulfate (DHEAS, nmol/L) and sex-hormone binding globulin (SHBG, nmol/L) were measured by radioimmunoassay (Testo-CT2, R-GM-100, DHEAS-CT and SHBG-RIACT, respectively; CIS Bio International, Gifsur-Yvette, France). Free androgen index (FAI) was calculated from total testosterone and SHBG levels using the formula $[($ testosterone $/ \mathrm{SHBG}) \times 100]$.

The plasma level of nitrotyrosine $(\mathrm{nmol} / \mathrm{L})$ was monitored by enzyme immunoassay (Oxis International Inc). The plasma thiol groups content $(\mu \mathrm{mol} / \mathrm{L})$ and glutathione peroxidase activity (GPX, U/L) were determined as decribed elsewhere. ${ }^{17,18}$

The standard oral glucose tolerance test (OGTT) was performed after an overnight fast, with $75 \mathrm{~g}$ of glucose. Glucose and insulin were determined at 0 , $30,60,90$ and $120 \mathrm{~min}$ of the test. The euglycemic hyperinsulinemic clamp (hereinafter "clamp") was performed two days after OGTT and also after the overnight fasting. In accordance with DeFronzo, the clamp was started with a primed continuous infusion of crystalline insulin (Novo Nordisk, Denmark) and was continued during $120 \mathrm{~min}$ at a rate of $0.1 \mathrm{U} / \mathrm{kg} / \mathrm{h} .{ }^{19}$ Blood glucose level was calculated from three glucose measurements 5 minutes apart, obtained immediately before the start of the study and was maintained at a euglycemic level between 4.5 and $5.6 \mathrm{mmol} / \mathrm{L}$ by variable infusion of $20 \%$ glucose. The whole body disposal rate (M, mg per kg per min) was determined as the mean of the glucose infusion rate during the last 30 min of the clamp (steady state rate), according to DeFronzo. ${ }^{19}$ In order to correct for any variations in the plasma insulin level, the insulin sensitivity index $(\mathrm{M} / \mathrm{I})$ was calculated by dividing the mean $\mathrm{M}$ by the steady state plasma insulin level during the last 30 min of the clamp and multiplying by $100{ }^{19}$

\section{Statistical analysis}

Statistical analysis was performed using the Statistical Package for the Social Sciences software (SPSS, version 17.0; SPSS Inc, Chicago, IL, USA). Comparison between groups was made by using the parametric t-test and nonparametric Mann-Whitney U-test, as appropriate. Association between different variables and oxidative stress markers were determined by using the Pearson correlation coefficient. A $p$ value $<0.05$ was considered statistically significant.

\section{RESULTS}

Clinical and biochemical parameters obtained from PCOS patients and healthy controls are shown in Table 1. There was no statistical difference in age, BMI, WC, fasting blood glucose, fibrinogen, CRP, SHBG, DHEAS and androstenedione between the PCOS group and the control group. Basal insulin and HOMA-IR were significantly higher and QUICKI significantly lower in PCOS patients in comparison to the controls $(15.14 \pm 6.96$ vs. $9.74 \pm 4.33 \mathrm{mmol} / \mathrm{L}$, $\mathrm{p}=0.007,3.18 \pm 1.55$ vs. $1.98 \pm 1.02, \mathrm{p}=0.007$, and $0.32 \pm 0.03$ vs. $0.36 \pm 0.06, \mathrm{p}=0.004$, respectively). The PCOS group in comparison to controls had significantly higher values of testosterone and FAI $(2.55$ \pm 1.04 vs. $1.83 \pm 0.77 \mathrm{nmol} / \mathrm{L}, \mathrm{p}=0.034$, and $8.66 \pm$ 8.51 vs. $3.35 \pm 1.36 \%, \mathrm{p}<0.01$, respectively).

The baseline differences of oxidative damage parameters and plasma GPX antioxidant enzyme activity between PCOS and normal subjects are displayed in Table 1. Nitrotyrosine and uric acid (UA) were significantly higher $(322.2 \pm 104.4 \mathrm{nmol} / \mathrm{L}$ vs. 266.5 $\pm 196.9 \mathrm{nmol} / \mathrm{L}, \mathrm{p}=0.048$, and $263.4 \pm 69.18 \mathrm{mmol} / \mathrm{L}$ vs. $203.3 \pm 31.45 \mathrm{mmol} / \mathrm{L}, \mathrm{p}=0.012$, respectively), while plasma thiol groups were lower in PCOS women 
Table 1. Basal clinical and biochemical parameters in non-obese PCOS patients and controls

\begin{tabular}{|c|c|c|c|}
\hline & $\begin{array}{l}\text { PCOS } \\
(n=36)\end{array}$ & $\begin{array}{c}\text { Controls } \\
(n=11)\end{array}$ & p value \\
\hline Age (years) & $26.31 \pm 4.25$ & $27.36 \pm 4.11$ & 0.460 \\
\hline BMI $\left(\mathrm{kg} / \mathrm{m}^{2}\right)$ & $21.99 \pm 3.17$ & $21.19 \pm 1.97$ & 0.474 \\
\hline $\begin{array}{l}\text { Waist circumference } \\
(\mathrm{cm})\end{array}$ & $74.47 \pm 8.78$ & $70.59 \pm 6.12$ & 0.161 \\
\hline $\begin{array}{l}\text { Basal glucose } \\
(\mathrm{mmol} / \mathrm{L})\end{array}$ & $4.69 \pm 0.49$ & $4.41 \pm 0.70$ & 0.214 \\
\hline Basal insulin (mU/L) & $15.14 \pm 6.96$ & $9.74 \pm 4.33$ & 0.007 \\
\hline HOMA-IR & $3.18 \pm 1.55$ & $1.98 \pm 1.02$ & 0.007 \\
\hline QUICKI & $0.32 \pm 0.03$ & $0.36 \pm 0.06$ & 0.004 \\
\hline ISI $_{\text {Matsuda }}$ & $4.59 \pm 2.61$ & $7.35 \pm 5.68$ & 0.030 \\
\hline Fibrinogen $(\mathrm{g} / \mathrm{L})$ & $3.39 \pm 0.92$ & $2.91 \pm 0.77$ & 0.134 \\
\hline $\mathrm{CRP}(\mathrm{mg} / \mathrm{L})$ & $1.16 \pm 1.15$ & $0.69 \pm 0.66$ & 0.246 \\
\hline Testosterone (nmol/L) & $2.55 \pm 1.04$ & $1.83 \pm 0.77$ & 0.034 \\
\hline SHBG (nmol/L) & $43.86 \pm 22.66$ & $60.92 \pm 29.33$ & 0.072 \\
\hline FAI & $8.66 \pm 8.51$ & $3.35 \pm 1.36$ & 0.001 \\
\hline DHEAS (nmol/L) & $8.18 \pm 4.09$ & $6.69 \pm 2.61$ & 0.304 \\
\hline $\begin{array}{l}\text { Androstenedione } \\
(\mathrm{ng} / \mathrm{mL})\end{array}$ & $3.36 \pm 1.29$ & $2.44 \pm 1.13$ & 0.059 \\
\hline $\mathrm{M}(\mathrm{mg} / \mathrm{kg} / \mathrm{min})^{*}$ & $9.79 \pm 4.01$ & $8.08 \pm 2.06$ & 0.184 \\
\hline $\begin{array}{l}\mathrm{M} / \mathrm{I}^{\S}(\mathrm{mg} / \mathrm{kg} / \mathrm{min} / \\
\mathrm{mU} / \mathrm{L}) \times 100\end{array}$ & $9.93 \pm 6.15$ & $6.89 \pm 4.56$ & 0.084 \\
\hline Thiol groups $(\mu \mathrm{mol} / \mathrm{L})$ & $7.42 \pm 1.20$ & $8.39 \pm 1.31$ & 0.043 \\
\hline Nitrotyrosine (nmol/L) & $322.20 \pm 104.38$ & $266.45 \pm 196.97$ & 0.048 \\
\hline Uric acid (mmol/L) & $263.42 \pm 69.18$ & $203.25 \pm 31.45$ & 0.012 \\
\hline GPX (U/L) & $376.52 \pm 110.49$ & $355.83 \pm 91.03$ & 0.516 \\
\hline
\end{tabular}

*M- whole body glucose disposal rate during last $30 \mathrm{~min}$ of euglycemic hyperinsulinemic clamp; ${ }^{\S} \mathrm{M} / \mathrm{I}-\mathrm{M}$ adjusted for the steady state plasma insulin level. compared to the controls $(7.42 \pm 1.20 \mu \mathrm{mol} / \mathrm{L}$ vs. 8.39 $\pm 1.31 \mu \mathrm{mol} / \mathrm{L}, \mathrm{p}=0.043)$. No significant difference was observed in antioxidant GPX activity in PCOS patients in comparison to controls $(p>0.05)$. In PCOS patients, the significant positive correlations were obtained for UA, as surrogate marker of xanthine oxidase activity with testosterone $(\mathrm{r}=0.385, \mathrm{p}=0.039)$, as well as indices of insulin resistance, specifically basal insulin, HOMA-IR, ISI and M/I (Table 2).

Acute hyperglycemia during OGTT induced alteration in both the parameters of oxidative damage of proteins and activity of antioxidant GPX activity in PCOS women. As depicted in Figure 1, the percent of change in plasma nitrotyrosine in response to the oral glucose challenge was significantly higher in women with PCOS compared with the weight-matched controls $(\mathrm{p}<0.05)$, while for the thiol groups this change did not reach statistical significance $(p=0.629)$. In contrast, OGTT induced a more pronounced fall in GPX activity in PCOS women in comparison to controls $(\mathrm{p}<0.05)$ (Figure 1). The alteration of oxidative stress parameters during hyperglycemia correlated with the hyperandrogenism present in PCOS women. Specifically, plasma levels of testosterone were positively correlated with the percentage of change in nitrotyrosine concentrations $(\mathrm{r}=0.543, \mathrm{p}=0.036)$ as well as with percentage of change in GPX activity during OGTT $(\mathrm{r}=-0.457, \mathrm{p}=0.025)$ (Figure 2). The data on the association between investigated oxidative stress markers and indices of insulin resistance are depicted in Table 2. When analyzing indices of insulin resistance, linear correlations were obtained between ISI with both HOMA-IR and QUICKI ( $\mathrm{r}=$

Table 2. Correlations of oxidative stress markers with insulin resistance indices in non-obese PCOS

\begin{tabular}{|c|c|c|c|c|c|c|c|c|c|c|}
\hline \multirow[b]{3}{*}{ Percentage of change* } & \multirow{2}{*}{\multicolumn{2}{|c|}{$\begin{array}{c}\text { Basal insulin } \\
(\mathrm{mU} / \mathrm{L})\end{array}$}} & \multicolumn{6}{|c|}{ OGTT } & \multirow{2}{*}{\multicolumn{2}{|c|}{$\begin{array}{c}\mathrm{IC} \\
\mathrm{M} / \mathrm{I} \\
(\mathrm{mg} / \mathrm{kg} / \mathrm{min} / \mathrm{mU} / \mathrm{L}) \times 100\end{array}$}} \\
\hline & & & \multicolumn{2}{|c|}{ HOMA-IR } & \multicolumn{2}{|c|}{ QUICKI } & \multicolumn{2}{|c|}{ ISI $_{\text {Matsuda }}$} & & \\
\hline & $\mathbf{r}$ & $\mathbf{p}$ & $\mathbf{r}$ & $\mathbf{p}$ & $\mathbf{r}$ & $\mathbf{p}$ & $\mathbf{r}$ & $\mathbf{p}$ & $\mathbf{r}$ & p \\
\hline Nitrotyrosine & 0.524 & 0.031 & 0.541 & 0.031 & 0.631 & 0.066 & 0.490 & 0.039 & 0.046 & 0.861 \\
\hline Thiol groups & 0.329 & 0.196 & 0.333 & 0.192 & 0.120 & 0.634 & 0.213 & 0.396 & 0.208 & 0.439 \\
\hline GPX activity & 0.356 & 0.161 & 0.325 & 0.203 & 0.383 & 0.159 & 0.607 & 0.021 & 0.115 & 0.696 \\
\hline 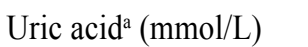 & 0.378 & 0.021 & 0.374 & 0.034 & 0.151 & 0.408 & 0.380 & 0.038 & 0.404 & 0.029 \\
\hline
\end{tabular}

*The percent of change in oxidative stress markers was determined when fasting samples were compared with the samples collected $2 \mathrm{~h}$ after OGTT or insulin clamp. ${ }^{\mathrm{a} B a s a l}$ values. OGTT: oral glucose tolerance test; IC: hyperinsulinemic clamp. 


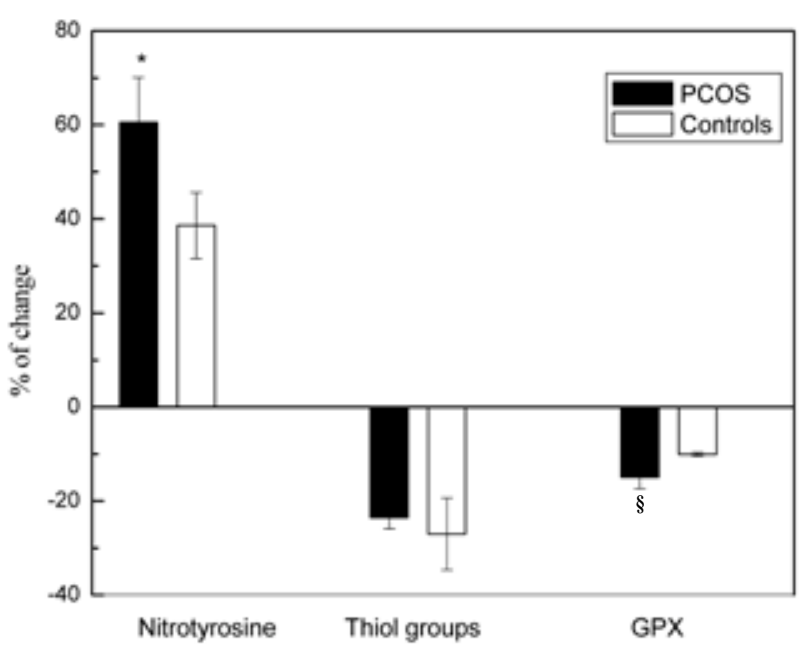

Figure 1. The percentage change in plasma nitrotyrosine, thiol groups and GPX activity when fasting samples were compared with the samples collected $2 \mathrm{~h}$ after glucose ingestion. *The percentage change in nitrotyrosine concentrations of PCOS women was greater compared with that of lean controls,

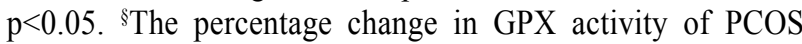
women showed a more pronounced decrease compared with that of lean controls, $\mathrm{p}<0.05$.

$-0.885, \mathrm{p}<0.001$ and $\mathrm{r}=0.886, \mathrm{p}<0.001$, respectively) as well as with $\mathrm{M} / \mathrm{I}(\mathrm{r}=0.425, \mathrm{p}=0.004)$.

In order to test the effect of hyperinsulinemia on the oxidative damage markers and antioxidant plasma GPX activity, we determined the alteration in nitrotyrosine, thiol groups and GPX activity during the euglycemic hyperinsulinemic clamp. No significant change in all tested parameters was observed during the clamp (data not shown).

\section{DISCUSSION}

In this study, we showed that both plasma markers of protein oxidative damage and GPX antioxidant activity are associated with measures of insulin resistance in young, non-obese PCOS women. During the oral glucose challenge, the alteration in oxidative stress markers significantly correlated with circulating testosterone.

Under fasting conditions, women with PCOS are exposed to subtle oxidative stress on account of the increased plasma nitrotyrosine and uric acid, decreased content of plasma thiol groups, followed by no changes in antioxidant glutathione peroxidase activity. Recent evidence suggests that major causes of increased generation of ROS in PCOS might be impairment of the mitochondrial electron transport chain ${ }^{20}$ together with increased enzymatic activities of the NADPH oxidase and xhantine oxidase..$^{5,21}$ Increased ROS production might affect the activity of redox-sensitive signaling pathways, such as the $\mathrm{PI}_{3} \mathrm{~K}-\mathrm{PDK}-1-\mathrm{Akt}$ signaling axis, which is involved in
A

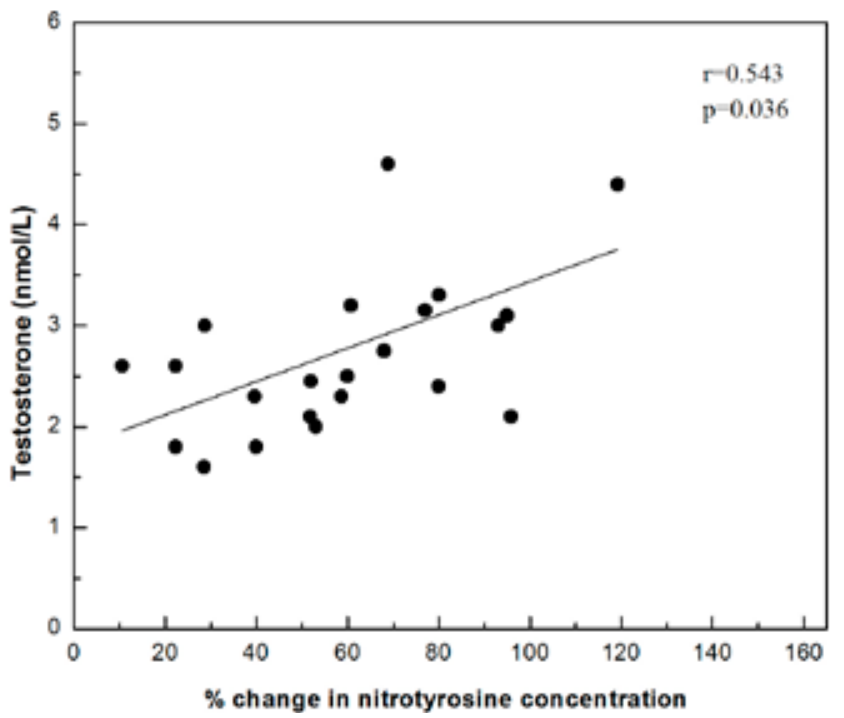

B

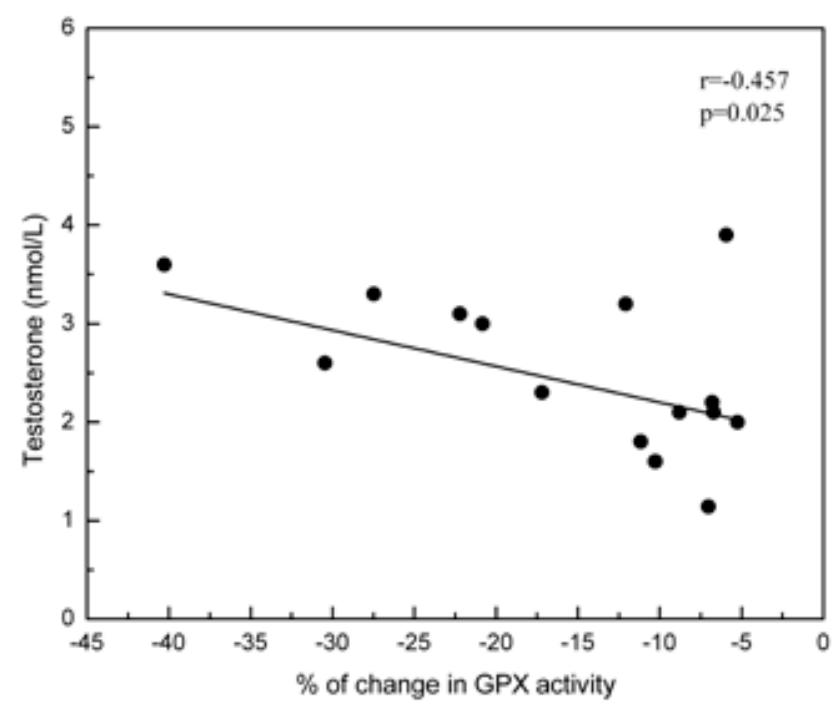

Figure 2. A. Correlation between testosterone and the percentage change in plasma nitrotyrosine. B. Correlation between testosterone and the percentage change in plasma GPX activity. The percentage change in plasma oxidative stress markers was determined when fasting samples were compared with the samples collected $2 \mathrm{~h}$ after OGTT. 
pleiotropic biological actions of insulin. ${ }^{22,23}$ As recently demonstrated in vitro on cultured human umbilical vein endothelial cells, a free radical peroxynitrite dose dependently inhibits Akt activity. ${ }^{23}$

Our results on increased concentrations of nytrotyrosine in healthy women as an indirect marker of peroxynitrite generation in response to acute hyperglycemia may be the normal in vivo response and are in accordance with the results of Ceriello et al (2008) ${ }^{24}$ However, the more pronounced increase in plasma nitrotyrosine during the oral glucose challenge in PCOS women in comparison with controls clearly implies that these women are more sensitive to oxidative stress in response to glucose ingestion. In this process, increased ROS generation with consequent decreased NO bioavailability may influence both insulin signaling and endothelial dysfunction. ${ }^{25}$ In our study, in the fasting state no changes were observed for plasma GPX activity in PCOS in comparison with healthy women, this being in accordance with recent findings. ${ }^{5,26}$ Another demonstration of increased protein oxidation during the glucose challenge is a significant decrease in GPX activity that was observed in PCOS compared to controls. This finding is biologically plausibile, since it has been shown that peroxynitrite itself can inhibit superoxide dismutase and other antioxidant molecules, leading to positive feedback cycles of oxidant generation and exacerbation of the oxidative cellular injury. ${ }^{27}$

Until now, the role of the antioxidant enzyme GPX in glucose metabolism and insulin function is still unclear. In the last decade, it has been explicitly confirmed that activity of the GPX3 isoenzyme, which accounts for a major part of the plasma activity, is down-regulated in obesity. ${ }^{28}$ Bearing in mind that GPX3 expression is greatly suppressed by prooxidative conditions present in obesity (i.e. high levels of TNF $\alpha$ and hypoxia), we chose normal weight PCOS women for the investigation of acute hyperglycemia on alteration in plasma GPX activity.

We did not show a direct effect of hyperinsulinemia during the euglycemic hyperinsulinemic clamp on the change in oxidative damage markers and antioxidant plasma GPX activity among our PCOS women. This could be related to the fact that we did not observe any differences in either $\mathrm{M}$ or $\mathrm{M} / \mathrm{I}$ index between investigated subjects. These results, which are in concordance with other studies, imply that lean PCOS could be hyperinsulinemic without being truly insulin resistant. ${ }^{29-31} \mathrm{M}$ and $\mathrm{M} / \mathrm{I}$ indexes represent predominantly insulin resistance in insulin-sensitive organs, such as skeletal muscle and adipose tissue, but not in the liver, as this method using high insulin levels almost completely suppresses hepatic glucose production, specifically in non-obese subjects, ${ }^{32}$ as were our PCOS women. A significant correlation between M/I and UA in our PCOS women can be explained by recent identification of the importance of hyperuricemia in predicting visceral obesity and insulin resistance. ${ }^{33}$ The most significant association that was found between oxidative stress markers,

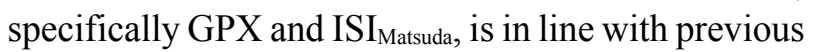
speculation on the influence of insulin resistance on the diminished antioxidant capacity in PCOS women. ${ }^{5}$ Future studies with clamp modifications are needed for more focused analyses of the possible link between the deleterious effects of hyperinsulinemia on change of the parameters of oxidative stress and consequent early vascular damage in PCOS women.

The main androgen in the circulation in women with PCOS is testosterone. Although some women with PCOS may have normal testosterone but increased levels of androstenedione and DHEAS, no such case was identified in our study. Our results regarding the association between plasma testosterone and alteration in oxidative stress parameters during acute hyperglycemia further confirm the link between oxidative stress and hyperandrogenism in this disorder. In vitro studies have shown that ovarian steroidogenic enzymes responsible for androgen production are stimulated by oxidative stress and inhibited by antioxidants. In fact, oxidative stress may exert a dual effect on theca cells. More pronounced oxidative stress as well as antioxidants (e.g. vitamin E succinate) inhibits proliferation of theca cells, while modest oxidative stress stimulates their proliferation in vitro. ${ }^{34}$ Furthermore, oxidative stress impairs insulin signaling, resulting in a compensatory hyperinsulinemia, which in turn further stimulates thecal steroidogenesis. ${ }^{35}$

In conclusion, our women with PCOS exhibited high ROS generation that is independent of obesity. This indicates that oxidative stress is a feature of 
PCOS per se and that it could contribute either to insulin resistance or to hyperandrogenemia. Among our non-obese women with PCOS, oxidative stress was related to hyperglycemia and circulating testosterone but seemed not to be related to the direct effect of hyperinsulinemia during the standard hyperinsulinemic euglycemic clamp.

\section{GRANTS}

This work was supported by grants 175052 and 41009 from the Serbian Ministry of Science and Technology.

\section{REFERENCES}

1. Agarwal A, Aponte-Mellado A, Premkumar BJ, Shaman A, Gupta S, 2012 The effects of oxidative stress on female reproduction: a review. Reprod Biol Endocrinol 10: 49 .

2. Gonzalez F, Rote NS, Minium J, Kirwan JP, 2006 Reactive oxygen species-induced oxidative stress in the development of insulin resistance and hyperandrogenism in polycystic ovary syndrome. J Clin Endocrinol Metab 91: 336-340.

3. Karadeniz M, Erdogan M, Tamsel S, et al, 2008 Oxidative stress markers in young patients with polycystic ovary syndrome, the relationship between insulin resistances. Exp Clin Endocrinol Diabetes 116: 231-235.

4. Kuscu NK, Var A, 2009 Oxidative stress but not endothelial dysfunction exists in non-obese, young group of patients with polycystic ovary syndrome. Acta Obstet Gynecol Scand 88: 612-617.

5. Macut D, Simic T, Lissounov A, et al, 2011 Insulin resistance in non-obese women with polycystic ovary syndrome: relation to byproducts of oxidative stress. Exp Clin Endocrinol Diabetes 119: 451-455.

6. Gonzalez F, 2012 Inflammation in Polycystic Ovary Syndrome: underpinning of insulin resistance and ovarian dysfunction. Steroids 77: 300-305.

7. Gonzalez F, Nair KS, Daniels JK, Basal E, Schimke JM, 2012 Hyperandrogenism sensitizes mononuclear cells to promote glucose-induced inflammation in lean reproductive-age women. Am J Physiol Endocrinol Metab 302: E297-306.

8. Chignalia AZ, Schuldt EZ, Camargo LL, et al, 2012 Testosterone induces vascular smooth muscle cell migration by NADPH oxidase and c-Src-dependent pathways. Hypertension 59: 1263-1271.

9. Rotterdam ESHRE/ASRM-Sponsored PCOS consensus workshop group, 2004 Revised 2003 consensus on diagnostic criteria and long-term health risks related to polycystic ovary syndrome (PCOS). Hum Reprod 19: 41-47.
10. Laven JS, Imani B, Eijkemans MJ, Fauser BC, 2002 New approach to polycystic ovary syndrome and other forms of anovulatory infertility. Obstet Gynecol Surv 57: 755-767.

11. Hatch R, Rosenfield RL, Kim MH, Tredway D, 1981 Hirsutism: implications, etiology, and management. Am J Obstet Gynecol 140: 815-830.

12. Macut D, Damjanovic S, Panidis D, et al, 2006 Oxidised low-density lipoprotein concentration - early marker of an altered lipid metabolism in young women with PCOS. Eur J Endocrinol 155: 131-136.

13. Balen AH, Laven JS, Tan SL, Dewailly D, 2003 Ultrasound assessment of the polycystic ovary: international consensus definitions. Hum Reprod Update 9: 505-514.

14. Matthews DR, Hosker JP, Rudenski AS, et al, 1985 Homeostasis model assessment: insulin resistance and beta-cell function from fasting plasma glucose and insulin concentrations in man. Diabetologia 28: 412-419.

15. Katz A, Nambi SS, Mather K, et al, 2000 Quantitative insulin sensitivity check index: a simple, accurate method for assessing insulin sensitivity in humans. J Clin Endocrinol Metab 85: 2402-2410.

16. Matsuda M, DeFronzo RA, 1999 Insulin sensitivity indices obtained from oral glucose tolerance testing: comparison with the euglycemic insulin clamp. Diabetes Care 22: 1462-1470.

17. Simic DV, Mimic-Oka J, Pljesa-Ercegovac M, et al, 2006 Byproducts of oxidative protein damage and antioxidant enzyme activities in plasma of patients with different degrees of essential hypertension. J Hum Hypertens 20: 149-155.

18. Radovanovic S, Savic-Radojevic A, Pljesa-Ercegovac M, et al, 2012 Markers of oxidative damage and antioxidant enzyme activities as predictors of morbidity and mortality in patients with chronic heart failure. $\mathbf{J}$ Card Fail 18: 493-501.

19. DeFronzo RA, Tobin JD, Andres R, 1979 Glucose clamp technique: a method for quantifying insulin secretion and resistance. Am J Physiol 237: E214-223.

20. Victor VM, Rocha M, Banuls C, et al, 2009 Mitochondrial complex I impairment in leukocytes from polycystic ovary syndrome patients with insulin resistance. J Clin Endocrinol Metab 94: 3505-3512.

21. Jiang F, Zhang Y, Dusting GJ, 2011 NADPH oxidasemediated redox signaling: roles in cellular stress response, stress tolerance, and tissue repair. Pharmacol Rev 63: 218-242.

22. Scherrer U, Randin D, Vollenweider P, Vollenweider L, Nicod P, 1994 Nitric oxide release accounts for insulin's vascular effects in humans. J Clin Invest 94: 2511-2515.

23. Song $\mathrm{P}, \mathrm{Wu} \mathrm{Y}, \mathrm{Xu} J$, et al, 2007 Reactive nitrogen species induced by hyperglycemia suppresses Akt signaling and triggers apoptosis by upregulating phosphatase PTEN (phosphatase and tensin homologue deleted on chromosome 10) in an LKB1-dependent manner. Circulation 116: $1585-1595$. 
24. Ceriello A, Esposito K, Piconi L, et al, 2008 Oscillating glucose is more deleterious to endothelial function and oxidative stress than mean glucose in normal and type 2 diabetic patients. Diabetes 57: 1349-1354.

25. Zou MH, Cohen R, Ullrich V, 2004 Peroxynitrite and vascular endothelial dysfunction in diabetes mellitus. Endothelium 11: 89-97.

26. Baskol G, Aygen E, Erdem F, et al, 2012 Assessment of paraoxonase 1, xanthine oxidase and glutathione peroxidase activities, nitric oxide and thiol levels in women with polycystic ovary syndrome. Acta Obstet Gynecol Scand 91: 326-330.

27. Griendling KK, Sorescu D, Lassegue B, Ushio-Fukai M, 2000 Modulation of protein kinase activity and gene expression by reactive oxygen species and their role in vascular physiology and pathophysiology. Arterioscler Thromb Vasc Biol 20: 2175-2183.

28. Fernandez-Sanchez A, Madrigal-Santillan E, Bautista $\mathrm{M}$, et al, 2011 Inflammation, oxidative stress, and obesity. Int J Mol Sci 12: 3117-3132.

29. Vrbikova J, Cibula D, Dvorakova K, et al, 2004 Insulin sensitivity in women with polycystic ovary syndrome. J Clin Endocrinol Metab 89: 2942-2945.
30. Ciampelli M, Fulghesu AM, Cucinelli F, et al, 1997 Heterogeneity in beta cell activity, hepatic insulin clearance and peripheral insulin sensitivity in women with polycystic ovary syndrome. Hum Reprod 12: 1897-1901.

31. Morin-Papunen LC, Vauhkonen I, Koivunen RM, Ruokonen A, Tapanainen JS, 2000 Insulin sensitivity, insulin secretion, and metabolic and hormonal parameters in healthy women and women with polycystic ovarian syndrome. Hum Reprod 15: 1266-1274.

32. Muniyappa R, Lee S, Chen H, Quon MJ, 2008 Current approaches for assessing insulin sensitivity and resistance in vivo: advantages, limitations, and appropriate usage. Am J Physiol Endocrinol Metab 294: E15-26.

33. Yoo TW, Sung KC, Shin HS, et al, 2005 Relationship between serum uric acid concentration and insulin resistance and metabolic syndrome. Circ J 69: 928-933.

34. Duleba AJ, Foyouzi N, Karaca M, et al, 2004 Proliferation of ovarian theca-interstitial cells is modulated by antioxidants and oxidative stress. Hum Reprod 19: 1519-1524.

35. Kodaman PH, Duleba AJ, 2008 HMG-CoA reductase inhibitors: do they have potential in the treatment of polycystic ovary syndrome? Drugs 68: 1771-1785. 